\title{
Wireless Sensor Network Components for Air Pollution Monitoring in the Urban Environment: Criteria and Analysis for Their Selection
}

\author{
Vendula Hejlová, Vít Voženílek \\ Department of Geoinformatics, Palacký University in Olomouc, Olomouc, Czech Republic \\ Email: venda.hejlova@gmail.com,vit.vozenilek@upol.cz
}

Received November 8, 2103; revised December 5, 2013; accepted December 11, 2013

Copyright (C) 2013 Vendula Hejlová, Vít Voženílek. This is an open access article distributed under the Creative Commons Attribution License, which permits unrestricted use, distribution, and reproduction in any medium, provided the original work is properly cited. In accordance of the Creative Commons Attribution License all Copyrights (C) 2013 are reserved for SCIRP and the owner of the intellectual property Vendula Hejlová, Vít Voženílek. All Copyright (C 2013 are guarded by law and by SCIRP as a guardian.

\begin{abstract}
Wireless sensor networks (WSNs) are fast evolving technology for collecting data in real time. Every wireless sensor network (WSN) is consisted of technical and software components which have to refer to the selected application. The paper focuses on the selection of WSN components. The WSN will be situated in the center of Olomouc City (OWSN). It will focus on measurements of harmful air pollutants and selected basic meteorological elements. The criteria for selection of WSN components including the most important parameters will be chosen and the final evaluation of the option utility will be made on the basis of multicriteria decision making process.
\end{abstract}

Keywords: Components of Wireless Sensor Network; Criterion; Multicriteria Analysis; Sensor Node

\section{Introduction}

WSNs are new fast evolving technology that has been successfully applied to the monitoring of selected phenomena in the wide range of fields trespassing to the socioeconomic and environmental domain. The WSNs in socioeconomic area are used for monitoring health state, park places, cars, energy in buildings and logistics. In the environmental direction they are used for detection of landslides, forest fires, air pollutants, volcanic activity, water quality, biodiversity, microclimate or irrigation planing [1-3].

The authors designed the WSN which will be situated in the centre of Olomouc city. This WSN will be used for monitoring air pollutants and selecting basic meteorological elements which influence concentration and dispersion of air pollutants.

The aim of this paper is to determine criteria for node (motherboard), sensor boards/sensors and gateway selection of the designed WSN. Technical components, their parts and software are evaluated on the basis of criteria which are defined for nodes (with included demands on the sensor boards/sensors) and gateway. Demands on software were included in the criteria for the selection of hardware components.

Every criterion has its own importance. The criteria for nodes are divided into eight groups which are rated according to their importance. The criteria for selection of gateway are divided into seven groups. Every group of criteria for nodes and gateways includes particular criteria. The ideal parameter for every criterion of Olomouc WSN (OWSN) is suggested. The ideal parameters of chosen criteria should be fulfilled in the case of the ideal option.

Manufacturers of WSN components and their products were searched. Every searched product (option) had to have fulfilled parameters related to the chosen criteria. Due to this step all options with their parameters were comparable because they could be evaluated on the basis of the same criteria with fulfilled parameters. Every criterion was evaluated by its importance in the selecting process. Finally, the weight computation and subsequent analysis were provided and the most suitable option was selected.

\section{Wireless Sensor Network Components}

Every WSN consists of two major groups of compo- 
nents - hardware (technical platform) and software.

The technical platform of the WSN is defined by nodes (motherboard) and gateway (base station). Every node consists of several parts: microprocessor, battery, communication unit, memory, built-in sensors and interface for connecting sensor boards/sensors [4]. Figure 1 shows the technical parts of the node. The sensors boards/sensors can be connected to the node [5]. Some nodes gather data from the other nodes and send them to the gateway. These nodes are called routers. The electromagnetic radio waves are used for the communication among nodes and between nodes and gateway. In recent research a vast number of WSN communication protocols operating in radio frequency has been developed [3]. Data are stored in the gateway or sent to the server for the long time storage. The nodes placed into the outdoor conditions have to have an ingress protection which protects the hardware components against the external influences [5].

Software of nodes controls hardware component, manages system resources and allows the use of applications [6].

Teams of experts deal with the application of the WSNs all around the world. WSNs for monitoring of harmful air pollutants have been tested and applied in Spain, Great Britain and Serbia. The new WSN is planned to be built in the Netherlands, Assen City. This technology has been mostly applied (except for Europe) in the USA, Taiwan, China and India.

The WSN for monitoring of air quality in Salamaca, Spain, is good example of effective network. It was built in the cooperation with CARTIF, European BIC Network, Salamanca City Hall and Research Advisory Group P\&G. This WSN is built on the components produced by the Spanish Company Libelium. Every node includes sensors for measuring temperature, relative humidity, $\mathrm{NO}_{2}, \mathrm{O}_{3}$, $\mathrm{CO}, \mathrm{PM}$ and noise level. Data are sent to the gateway

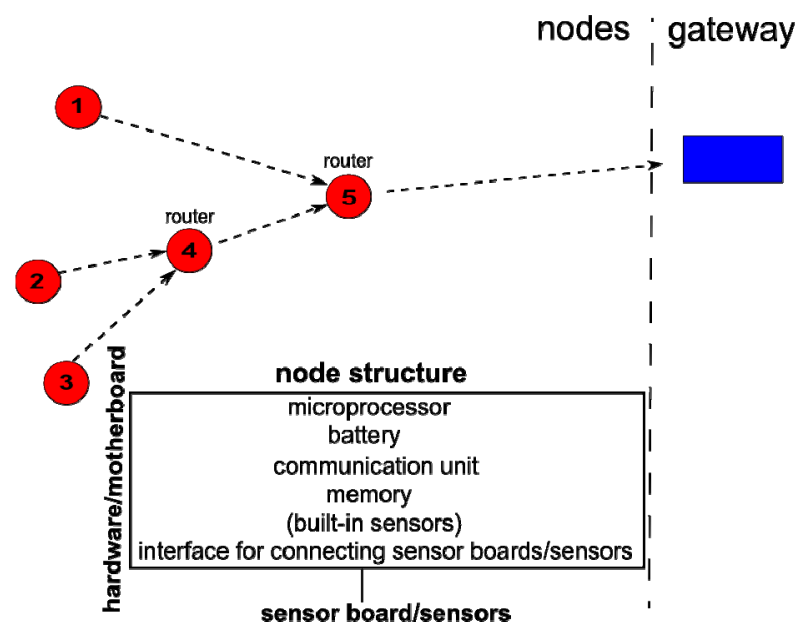

Figure 1. Technical parts of the wireless sensor node. from which they are resent to the server for long time storage. Nodes can react to overstepping of the allowed limits which are set for every measured element. If the limit is exceeded, the emergency message is sent to the gateway and the warning is issued. This WSN was created in 2011 within the RESCATAME project using capabilities of the Spanish producer [7,8].

The specially developed nodes for monitoring of air pollution were used in London in 2007. The sensors for monitoring $\mathrm{SO}_{2}, \mathrm{NO}, \mathrm{NO}_{2}, \mathrm{O}_{3}, \mathrm{NH}_{3}$ and benzene were connected to the nodes [9]. The prototype of the WSN which used GUSTO nodes was tested in the Cambridge University Campus in 2008. The nodes carried the sensors for monitoring $\mathrm{CO}, \mathrm{CO}_{2}, \mathrm{NO}_{2}$ and GPS receiver. Data were sent from the nodes to the central storage through the mobile network $[10,11]$.

In Serbia there are also used nodes with sensors produced by Libelium. The nodes are situated on the moving buses so that the movement of the bus can be traced. The information about position of buses can be displayed in a mobile application [12].

The great emphasis is placed on the usage of WSNs for monitoring of air pollutants in Taiwan. The nodes, called OCTOPUS II, were developed in cooperation between government and universities. These nodes were equipped with sensors produced by $\mathrm{e} 2 \mathrm{v}$ for $\mathrm{CO}$ measureing [11].

The high attention for using WSNs has been focused in Indian and Chinese towns. The increasing number of cars causes more harmful pollutants in the air. In Indian Hyderabad City there are used the nodes and sensors produced by Libelium [13]. The motherboards Mica2 which are produced by Crossbow Company are used for monitoring in Nagpur City, India. The sensors were specially developed for this application [14]. The University in Cinncinati is oriented on the monitoring of air pollutants using the MICAz nodes which are produced by Crossbow Company. They use the sensors of KWJ Engineering [15].

In above-mentioned studies there was given only one reason for the selection of components. This reason pointed to the type of application of the WSN and the compatibility of sensors measuring air pollutants and the motherboard. The greatest attention in the process of wireless sensor components selection is aimed at nodes. If the commercially offered options did not meet requirements for the application, the nodes were developed as a part of project as in the case of London wireless sensor network $[10,11]$.

\section{The Selection of WSN Components}

The selection of the WSN components is very important because it is a crucial decision. On its basis the meas- 
urements of harmful air pollutants in the urban environment will be performed. Pre-selection steps involve:

- determination of the purpose of building

- determination of the number of nodes

- choosing the localization of the nodes

- searching for the producers (analyzing commercially offered components and comparing their functionality)

- defining the criteria for the evaluation of selected options

- defining the ideal option

- comparing criteria parameters of offered options to the ideal (suggested) one (intended configuration)

\section{Criteria for the Wireless Sensor Network Selection}

Criteria were formulated according to the aim and purpose of the Olomouc WSN (OWSN). Suitably selected criteria serve as a basis for the determination of the fitted option with using the multicriteria analysis decision making process. This method is used for the selection of the most suitable product (option) from the possible solutions $[16,17]$.

A criterion in a decision making process is called the scale and it is used for the comparison of the chosen option parameters. Every option should have fulfilled the criteria parameters. Criteria have to cover the most suitable parameters which have to be completed so that hard expressible criteria can be selected. The importance of every criterion which is a basis for the determination of its weight have to be indetified. The weight shows the importance of the selected criteria in the decision making process and it is written as a positive real number $[16,18]$. There is always an uncertainty in the process of determination of criteria [19].

The weights of criteria were determined by two methods: The Order and The Compensation Method. Weights of every criterion determined by these methods were compared. The method which was selected for the determination of the final result is called The Weighted Sum Method. The selected method is ordered to the group of methods based on the weighted average of evaluation. The final result was computed with The Aggregated Utility Function which is one type of the advanced computational algorithms $[16,18]$. The weights computed by The Order and The Compensation Methods were used to the computation which determines the order of options.

Factors like node size, price and energy consumption play the most important role in the selection of the WSN nodes. According to [20] "the nodes could be in some cases smaller than $1 \mathrm{~cm}^{3}$, with the weight lower than 100 $\mathrm{g}$, cheaper than 1 USD and the energy consumption lower than $100 \mu \mathrm{W}$." Sensor boards/sensors have to complete the requirements for the wireless sensor application and to measure elements which are suitable for the chosen task. The gateway has to be flexible, with a large memory size and it has to have a large communication range with the possibility of connecting through ethernet to the server.

The computation of the best option was made for nodes. The requirements for software and the sensor boards/sensors were added to the ones which are related to the nodes. It is presumed that the other WSN components will be provided by the same company like the selected nodes. If the result will not be unambiguously the analysis of the other components and companies will be provided. The most suitable commercially offered option will be applied for the monitoring in Olomouc City.

\subsection{Criteria for Nodes Selection}

The nodes are the basic building unit of the WSN so that the majority of requirements are related to this kind of hardware component. Eight groups of criteria for nodes were defined and they can be seen in Table 1. These groups were thematically divided. The importance of each criterion was specified on the basis of defined parameters for the ideal option and the following consultation with experts.

The first group of criteria deals with the offered sensor boards/sensors because the sensors for the measurement of harmful air pollutants have to be connected to the motherboard. The first criterion of this group relates to the possibilities of connecting sensors which measure elements fulfilling the purpose of the application. It is evaluated if the sensors are produced by the same producer, like the motherboard, or if they have to be bought from another producer. The count of sensors connected to the motherboard shows the maximum amount of observed elements. Sensor measurement interval differs from elements because some of them change more quickly than the others. Calibration of sensors is very important because it is made in the laboratory conditions with the knowledge of calibration curves so that it should be provided by the producer of sensors. Sensors can be built in the motherboard. These sensors are not suitable for external monitoring because they are covered in the enclosure and they measure inside nodes parameters.

The second group of criteria is called communication models. The first and the most important criterion from this group is that nodes have to communicate not only with the gateway (or server) but with one another. Nodes sending data directly to the gateway or sever do not fulfill all requirements for the WSN. Their configuration can be considered to the star topology with the long distance data transmission. In the most of cases they 
Table 1. Criteria for nodes selection.

\begin{tabular}{|c|c|c|}
\hline Criteria Group Number & Criteria Group & Criteria for Nodes Selection \\
\hline \multirow[t]{7}{*}{1} & Sensor boards/sensors & \\
\hline & & sensor board for monitoring of air pollutants from the same producer \\
\hline & & possibilities for connecting sensors for monitoring of pollutants \\
\hline & & count of connected sensor boards/sensors \\
\hline & & sensor measurement interval [min] \\
\hline & & calibration \\
\hline & & built-in sensors \\
\hline \multirow[t]{5}{*}{2} & Communication models & \\
\hline & & communication among nodes \\
\hline & & communication possibilities \\
\hline & & communication range $[\mathrm{m}]$ \\
\hline & & topology \\
\hline \multirow[t]{4}{*}{3} & Energy sources & \\
\hline & & energy source \\
\hline & & battery life [year] \\
\hline & & energy consumption \\
\hline \multirow[t]{3}{*}{4} & Environmental resistance & \\
\hline & & storage temperature $\left[{ }^{\circ} \mathrm{C}\right]$ \\
\hline & & protection \\
\hline \multirow[t]{5}{*}{5} & Technical aspects & \\
\hline & & programming skills \\
\hline & & software \\
\hline & & memory size $[\mathrm{KB}]$ \\
\hline & & $\mathrm{I} / \mathrm{O}$ \\
\hline \multirow[t]{4}{*}{6} & Expansion options & \\
\hline & & flexibility \\
\hline & & sensor boards/sensors change \\
\hline & & GPS \\
\hline \multirow[t]{3}{*}{7} & Physical parameters & \\
\hline & & size $[\mathrm{mm}]$ \\
\hline & & weight $[\mathrm{g}]$ \\
\hline \multirow[t]{2}{*}{8} & Price & \\
\hline & & price for one node $[€]$ \\
\hline
\end{tabular}

communicate through mobile or internet network. If the protocols with the shorter range are used, then all nodes have to be placed in a short distance from the gateway [21]. The communication among the nodes can be performed on short or long distances depending on the used protocol. The nodes which send data through the other nodes are called routers. The communication between nodes and gateway uses the same protocol as the communication among nodes. All measured data are gathered in the gateway and sent to the server. This type of communication can be performed for short or long distances. The most common and the safest communication between gateway and server is performed using ethernet. The selected type of the communication deals with the communication range which shows the maximal range for data sending. Topology is the last criterion in this group. Two most commonly used types of topology are tree and mesh topology.

Energy sources are included in the third group of criteria. The most important criterion in this group deals with the possibilities of energy sources. There are a lot of ways how to charge the nodes. The first type of charging is by the various types of batteries, the second one by electricity network and the third one by USB or some other computer compatible connector. The power options are limited in the environmental conditions. The most commonly used form of charging includes batteries. The battery life depends on the energy consumption which depends on the selected mode and its occupancy. The major influence on the battery life has the fact if the node 
is the router or not. It is important to know if there is a possibility of charging battery by solar panel. Due to the solar panel battery of the nodes is continuously charged.

The fourth group of the criteria is oriented on the availability of nodes to resist the environmental influences such as rain, dust, temperature extremes etc. The storage temperature and the protection of nodes belong to these demands. It is necessary to obtain data during the whole year in all kinds of weather conditions. The external influences depend on the part of the world where the nodes are installed. The protection from the effects of the outer environment is made by the enclosure which must not have an influence on the measured values but it has to protect the hardware of the node.

The fifth group is based on the technical aspects of the WSN. The first criterion in this group is called the level of programming skills. This level can be low, middle or high. It depends on the pre-installed software parts in the node from the producer. The user has to have the option to interfere to the program code and suit it to its own application. The criterion on memory size is very important when the data are stored in the node for a longer time and they are not directly sent to the gateway. Input and output capabilities relate to the possibilities of accessing to the node.

The possibilities of WSN extension are summarized in the sixth group. Criteria like flexibility, possibility of sensor changing and adding a GPS unit are summarized in this group. The WSN can be extended by the number of nodes in the same place or it can expand to the larger area. Sensors or GPS unit can be added to the node.

Physical parameters are summarized in the seventh group of criteria. The first criterion is connected to the size of the node. The second one focuses on the weight of the node. These two parameters are important in the case that the nodes have to be hidden so that they do not arouse the attention of vandals [22].

The eight group of criteria is aimed at the price of node. The price of one node depends on a lot of demands such as application because this demand depends on the number of nodes in the field and the selection of sensors for the measured values of the elements. The price of one node ranges from 99 to $600 €$. The price depends on the equipment of node and its measurement capabilities.

\subsection{Criteria for Gateway Selection}

Requirements for the gateway selection are very similar to those which are placed on nodes (Table 2). Demand on sensors selection does not have to be solved in the case of gateway. Criteria for gateway selection are divided into seven groups.

Table 2. Criteria for gateway selection.

\begin{tabular}{|c|c|c|c|}
\hline Criteria Group Number & Criteria Group & Criteria for Nodes Selection & Increasing/Decreasing/Boolean Preference \\
\hline \multirow[t]{3}{*}{1} & Communication models & & \\
\hline & & communication possibilities & $\max$ \\
\hline & & topology & type \\
\hline \multirow[t]{4}{*}{2} & Energy sources & & \\
\hline & & energy source & $\max$ \\
\hline & & battery life [year] & $\max$ \\
\hline & & energy consumption & $\min$ \\
\hline \multirow[t]{3}{*}{3} & Environmental resistance & & \\
\hline & & storage temperature $\left[{ }^{\circ} \mathrm{C}\right]$ & $\max$ \\
\hline & & protection & yes \\
\hline \multirow[t]{5}{*}{4} & Technical aspects & & \\
\hline & & programming skills & $\min$ \\
\hline & & software & type \\
\hline & & memory size $[\mathrm{KB}]$ & $\max$ \\
\hline & & security & $\max$ \\
\hline \multirow[t]{4}{*}{5} & Expansion options & & \\
\hline & & flexibility & $\max$ \\
\hline & & sensor boards/sensors change & yes \\
\hline & & GPS & yes \\
\hline \multirow[t]{3}{*}{6} & Physical parameters & & \\
\hline & & size $[\mathrm{mm}]$ & $\min$ \\
\hline & & weight $[\mathrm{g}]$ & $\min$ \\
\hline \multirow[t]{2}{*}{7} & Price & & \\
\hline & & price for one gateway [€] & $\min$ \\
\hline
\end{tabular}


The first group of criteria is aimed at the communication models. The possibilities of communication between nodes and gateway, gateway and server are involved in this group. Topology possibilities are taken into account.

Energy sources are included in the second group of criteria. The first criterion deals with power options. Gateway can be powered by electricity, because it can be situated in the indoor environment, because this component does not measure outside parameters. Gateway can be also powered by batteries and in this case it is necessary to consider battery life which should be high with low energy consumption.

The third group of criteria deals with resistance of gateway against the external influences. The criteria dealing with operational temperature and protected encapsulation are sorted into this group. The operational temperature must correspond with conditions of the place where the gateway is situated. Only a small number of gateways is suitable to be placed into the outdoor conditions. Encapsulation is necessary if the gateway is located in the external conditions.

Technical aspects are involved in the fourth group of criteria. The first criterion in this group deals with the programming skills of the user. Basic interface of gateway has to be programmed. There have to be possibility of intervention to the program code. The memory size is considered in the case of gateway. Measured values can be stored in gateway for a long time, before they are sent to the server. The security has to be taken into account because in the gateway are stored a lot of data and they must not be lost.

The fifth group of criteria is aimed at the possibilities of expansion. Flexibility and extension by additional components like GPS receiver are involved in this group.

Physical parameters like size and weight of a node are included in the sixth group of criteria. The small size and weight are important if the nodes are situated in the external conditions and the gateway must not be immediately spotted or have to be placed in the higher position like roof or the top of traffic lamp.

The last group of criteria deals with price. The price depends on possibilities of communication which enables to connect the gateway with nodes and server and memory size.

\section{Requirements for the Wireless Sensor Network Components in Olomouc City}

The major aim of Olomouc WSN (OWSN) is the monitoring of air pollutants. The ideal parameters for every criterion will be suggested only for the nodes which will be further evaluated. This WSN has to complete the criteria evaluated by the highest values. Every criterion has suggested the ideal parameter which is shown in Table 3.
Fifteen nodes are planned to be placed in the centre of Olomouc City. These nodes will be situated around busy roads and in the nearby park. Their area of localization is shown in Figure 2.

The most significant requirements are included in the first four groups of criteria. The first group is the most important because it solves if the sensor boards/sensors measuring the air pollutants can be connected. The second group shows the possibilities of communication and the third one examines the energy possibilities. The possibility of encapsulation is very important for the external monitoring.

Harmful air pollutants and basic meteorological elements observed by the OWSN should be in the ideal case: $\mathrm{CO}_{2}, \mathrm{NO}_{2}, \mathrm{O}_{3}, \mathrm{CO}, \mathrm{CH}_{4}$, temperature, relative humidity, solar radiation, wind speed and wind direction. The list of ideally observed elements was made in the cooperation with the Czech Hydrometeorological Institute, Ostrava Office. The distribution, concentration and dispersion of the chosen air pollutants and meteorological geographical elements in the centre of Olomouc City will be observed.

Another significant request belongs to the second group of criteria called communication models. In this criterion there has to be confirmed the requirement for the possibilities of communication non licensed area in the Czech Republic (3.4 or $5 \mathrm{GHz}$ ). The usage of Zigbee protocol is necessary. This protocol is used for short and middle distance transmissions. The distance between the nodes in the OWSN should be at least 300 meters.

In the third group of criteria which is about energy sources there is the most important requirement for using battery power as an energy source.

The fourth group deals with environmental resistance which is very important when the nodes are placed in the external conditions.

\section{Commercially Offered Components}

A lot of companies offer WSN components but only a few of them can offer nodes which communicate with each other. The combination of components from different companies could bring problems with the installation and subsequent commissioning due to incompatibility among nodes and sensor boards. All products offered by ten companies were taken into account (Table 4).

The most suitable options were selected from 28 types of nodes, 52 sensor boards/sensors and 9 gateways. All these components were evaluated on the basis of above selected criteria. The highest attention is aimed at the sensor nodes because they create the most important part of the whole system. The chosen nodes are completed with sensor boards/sensors from the same producer.

The chosen criteria were not fulfilled in the case of all 
Table 3. Parameters suggested for the OWSN.

\begin{tabular}{|c|c|c|c|}
\hline Criteria Group Number & Criteria Group & Criteria for Nodes Selection & OWSN requirements \\
\hline \multirow[t]{7}{*}{1} & Sensor boards/sensor & & \\
\hline & & $\begin{array}{l}\text { sensor board for monitoring of pollutants } \\
\text { from the same producer }\end{array}$ & yes \\
\hline & & $\begin{array}{l}\text { possibilities for connecting sensors for } \\
\text { monitoring of pollutants }\end{array}$ & - \\
\hline & & count of connected sensor boards/sensors & $\min 6$ \\
\hline & & sensor measurement interval [min] & 15 \\
\hline & & calibration & yes \\
\hline & & built-in sensors & thermometer, akcelerometer \\
\hline \multirow[t]{5}{*}{2} & Communication models & & \\
\hline & & communication among nodes & yes \\
\hline & & communication possibilities & $\begin{array}{l}\text { Zigbee protocol, communication in } \\
\text { the range } 3.4 \mathrm{GHz} \text { or } 5 \mathrm{GHz}\end{array}$ \\
\hline & & communication range $[\mathrm{m}]$ & 300 \\
\hline & & topology & tree \\
\hline \multirow[t]{4}{*}{3} & Energy sources & & \\
\hline & & energy source & battery \\
\hline & & battery life [year] & one in the operation \\
\hline & & energy consumption & the lowest \\
\hline \multirow[t]{3}{*}{4} & Environmental resistance & & \\
\hline & & storage temperature $\left[{ }^{\circ} \mathrm{C}\right]$ & $-30-+40$ \\
\hline & & protection & yes \\
\hline \multirow[t]{5}{*}{5} & Technical aspects & & \\
\hline & & programming skills & low \\
\hline & & software & open source \\
\hline & & memory size $[\mathrm{KB}]$ & 600 \\
\hline & & $\mathrm{I} / \mathrm{O}$ & must have USB connector \\
\hline \multirow[t]{4}{*}{6} & Expansion options & & \\
\hline & & flexibility & yes \\
\hline & & sensor boards/sensors change & yes \\
\hline & & GPS & no, but there must be possibility for buying \\
\hline \multirow[t]{3}{*}{7} & Physical parameters & & \\
\hline & & size $[\mathrm{mm}]$ & $100 \times 100 \times 100$ \\
\hline & & weight $[\mathrm{g}]$ & 100 \\
\hline \multirow[t]{2}{*}{8} & Price & & \\
\hline & & price for one node $[€]$ & 300 \\
\hline
\end{tabular}




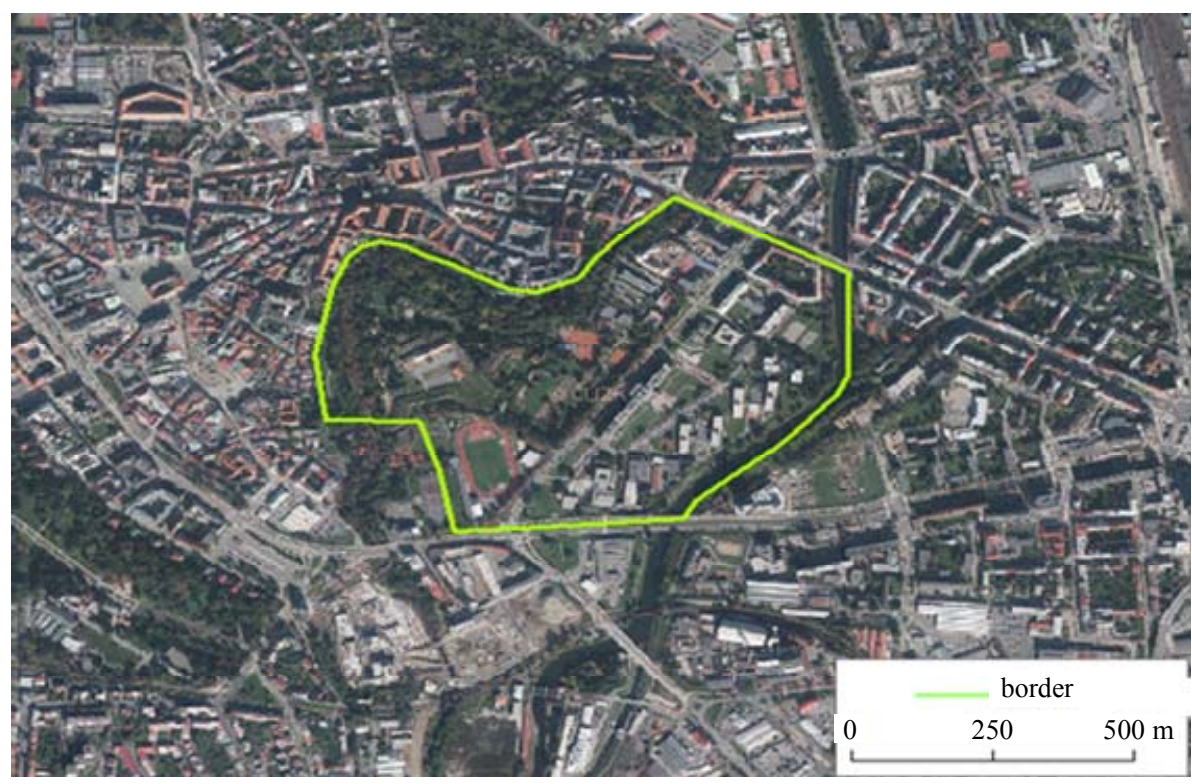

Figure 2. Area covered by nodes.

Table 4. Major producers of WSNs.

\begin{tabular}{cccc}
\hline Producer & State & Producer & State \\
\hline Libelium & Spain & Dust Inc. & USA \\
Memsic & USA & CSIRO & Australia \\
Crossbow & USA & Sun Microsystems & USA \\
TinyNode & Switzerland & Shimmer & Ireland \\
AdvanticSys & Switzerland & SilliconLabs & USA \\
\hline
\end{tabular}

products (options) because the needed information is not provided by the producer. Nodes which had fulfilled at least $80 \%$ from the chosen criteria were selected to the evaluation. 15 nodes have completed this requirement. They are produced by 5 companies.

The criteria were used for the evaluation of producers of WSN components. It is necessary to know how they behave to the potential customer. It was evaluated if the distributor communicates with the user. Scale from 1 to 5 was chosen to evaluate how many days the sending answer has lasted. If the answer was not accepted in five days this company was evaluated by number 5 . The second criterion is aimed at the structure of the answer. The answer can be either blunt and only correspond to the desired questions, or may contain additional questions towards the user and additional information. The evaluation was made in the scale from 1 to 5 (Table 5).

\section{Results}

The criteria for selecting the most suitable components were simplified. This step was made because the parameters of all options have to be easily comparable. The utility computing was made for nodes which had at least $80 \%$ of criteria fulfilled.

The weights of the criteria which come from their importance were determined. Two kinds of methods were used for the determination of weights. The first method is known as The Rank Based Method, the second one as The Compensation Method. The weights determined by these methods can be compared because they were computed for all criteria. Their values are shown in Table 6 and they are graphically compared in Figure 3. The highest values of weights were computed in the cases of the most important criteria. The differences between weight values computed by two methods are not so significant in the cases of middle important criteria. The most important criteria have higher weight values computed by The Rank Based Method. The least important criteria have higher values of weights computed by The Compensation Method. The highest difference between values computed by these two methods was in the case of criteria called Sensor boards/sensors from the same producer.

The Utility of the selected 15 options was computed by The Weighted Sum Method and The Aggregation Function. The utilities of the selected options with their producers are shown in Table 7 and compared in Figure 4. The node called Waspmote Plug\&Sense has the highest utility value of all options. This node is produced by the Spanish Company called Libelium. Nodes which have the second highest value of utility are produced by the same company as the first option and they are called Waspmote PRO nodes. The basic parameters of these two kinds of nodes are the same but the evaluation of Waspmote PRO was reduced by the criterion which 
Table 5. The evaluation of the producers with at least $80 \%$ of criteria fulfilled.

\begin{tabular}{lcccccc}
\hline & & Libelium & Memsic & Crossbow & AdvanticSys & TinyNode \\
\hline 1 & Communicate company with user & 1 & 1 & 5 & 4 & 5 \\
2 & Structure of the answer & 1 & 1 & 5 & 2 & 5 \\
\hline
\end{tabular}

Table 6. The weights of criteria determined by two methods.

\begin{tabular}{|c|c|c|c|c|c|}
\hline $\begin{array}{l}\text { Criteria Group } \\
\text { Number }\end{array}$ & Criteria Group & Criteria for Nodes Selection & $\begin{array}{l}\text { Increasing/Decreasing/ } \\
\text { Boolean Preference }\end{array}$ & $\begin{array}{l}\text { Weight Rank } \\
\text { Based Method }\end{array}$ & $\begin{array}{c}\text { Weight } \\
\text { Comp. Method }\end{array}$ \\
\hline \multirow[t]{5}{*}{1} & Sensor boards/sensors & & & & \\
\hline & & $\begin{array}{l}\text { sensor board for monitoring of pollutants } \\
\text { from the producer }\end{array}$ & yes & 0.09 & 0.070 \\
\hline & & $\begin{array}{l}\text { possibilities for connecting sensors for } \\
\text { monitoring of pollutants }\end{array}$ & - & 0.076 & 0.066 \\
\hline & & calibration & yes & 0.047 & 0.055 \\
\hline & & built-in sensors & yes & 0.023 & 0.039 \\
\hline \multirow[t]{5}{*}{2} & Communication models & & & & \\
\hline & & communication among nodes & yes & 0.090 & 0.070 \\
\hline & & Zigbee protocol & yes & 0.076 & 0.064 \\
\hline & & communication in $3.4 \mathrm{GHz}$ or $5 \mathrm{GHz}$ & yes & 0.083 & 0.069 \\
\hline & & middle values of communication range $[\mathrm{m}]$ & yes & 0.073 & 0.063 \\
\hline \multirow[t]{4}{*}{3} & Energy sources & & & & \\
\hline & & battery powered & yes & 0.063 & 0.059 \\
\hline & & battery life [months] & $\max$ & 0.060 & 0.057 \\
\hline & & is solar panel possible & yes & 0.063 & 0.058 \\
\hline \multirow[t]{3}{*}{4} & Environm. resistance & & & & \\
\hline & & $\begin{array}{l}\text { is in operational range interval } \\
\qquad-30-+40\left[{ }^{\circ} \mathrm{C}\right]\end{array}$ & yes & 0.050 & 0.056 \\
\hline & & protection & yes & 0.050 & 0.055 \\
\hline \multirow[t]{3}{*}{5} & Technical aspects & & & & \\
\hline & & programming skills & $\min$ & 0.040 & 0.048 \\
\hline & & memory size & $\max$ & 0.030 & 0.049 \\
\hline \multirow[t]{2}{*}{6} & Expansion options & & & & \\
\hline & & GPS, change of sensors, flexibility & yes & 0.030 & 0.042 \\
\hline \multirow[t]{3}{*}{7} & Physical parameters & & & & \\
\hline & & size $[\mathrm{mm}]$ & $\min$ & 0.020 & 0.020 \\
\hline & & weight $[\mathrm{g}]$ & $\min$ & 0.013 & 0.021 \\
\hline \multirow[t]{2}{*}{8} & Price & & & & \\
\hline & & price $[€]$ & $\min$ & 0.023 & 0.038 \\
\hline
\end{tabular}




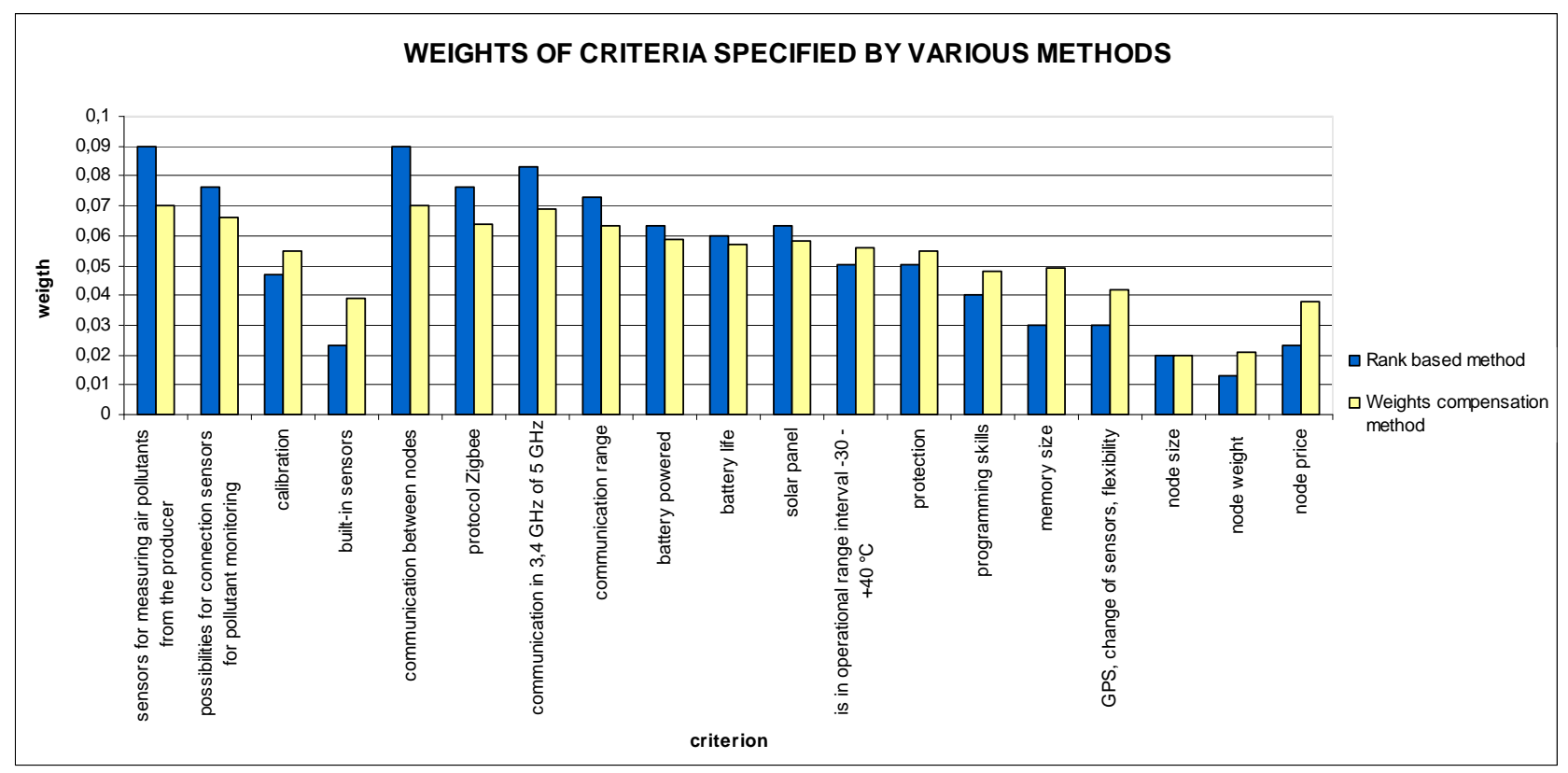

Figure 3. Weights of criteria determined by different methods.

Table 7. The utility of selected options.

\begin{tabular}{|c|c|c|c|}
\hline Nodes name & Producer & Utility (The Rank Based Method) & Utility (The Compensation Method) \\
\hline Waspmote PRO & Libelium & 0.710 & 0.712 \\
\hline Waspmote Plug \& Sense & Libelium & 0.749 & 0.763 \\
\hline $\mathrm{MICAz}$ & Memsic & 0.468 & 0.460 \\
\hline LOTUS & Memsic & 0.572 & 0.578 \\
\hline TelosB & Memsic & 0.544 & 0.562 \\
\hline IRIS & Memsic & 0.486 & 0.488 \\
\hline IRIS (eKo Standard) & Memsic & 0.572 & 0.560 \\
\hline IRIS (eKo Long Range) & Memsic & 0.599 & 0.580 \\
\hline IMOTE2 & Crossbow & 0.466 & 0.453 \\
\hline MICA2 & Crossbow & 0.336 & 0.358 \\
\hline MEP-SYS multisensor & Crossbow & 0.354 & 0.436 \\
\hline MEP-SYS temp-hum & Crossbow & 0.355 & 0.437 \\
\hline TinyNode586 & TinyNode & 0.558 & 0.568 \\
\hline XM100 & AdvaticSys & 0.638 & 0.638 \\
\hline CM5000 & AdvaticSys & 0.637 & 0.637 \\
\hline
\end{tabular}

includes node encapsulation. The third highest utility was reached by the nodes produced by the AdvanticSys Company. This company offers two kinds of nodes which reached the same result. The reason for the lower utility is the fact that this node does not have the encapsulation as the first mentioned option. Only these two companies offer nodes and sensor boards/sensors which measure the amount of air pollution. The requirement for the sensor boards/sensors measuring the air pollution from the same producer as the node has a high weight and that is the reason why these products are on the top of the result list. The eKo nodes are produced by Memsic. These nodes are encapsulated so they can be directly placed in the outdoor conditions. This criterion was in 


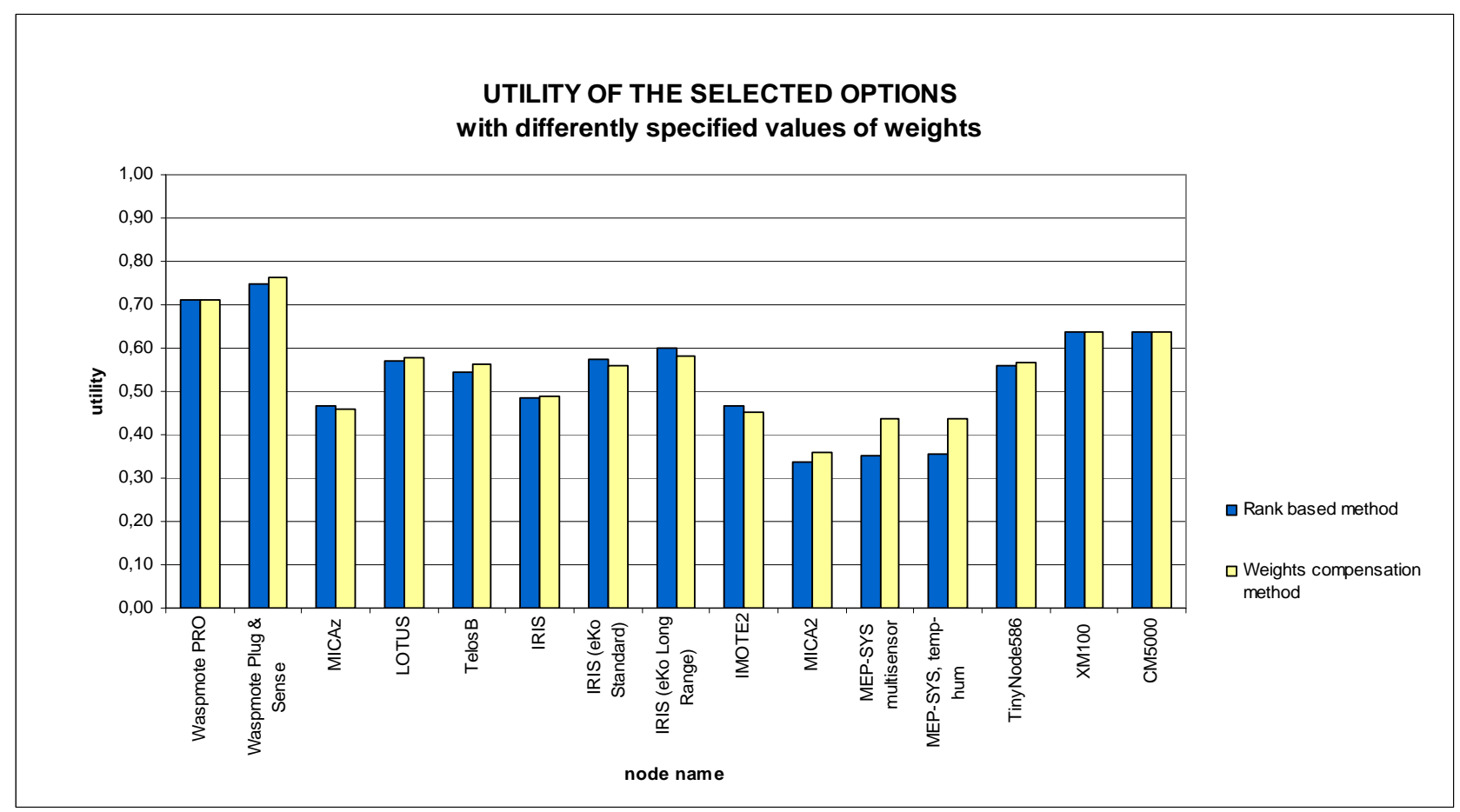

Figure 4. Utility of selected options.

the overall evaluation highlighted. The node called MICA2 has the lowest utility. This node communicates in the spectrum which is not allowed in the Czech Republic. Requirement for the communication in the allowed spectrum has a high weight value. MEP-SYS are nodes which have the second lowest utility. These nodes are encapsulated but it is not possible to change their sensors and the sensors for the monitoring of harmful air pollution.

\section{Conclusion and Discussion}

The WSN components selection for the particular application is a very important part of the whole project and certain attention must be paid to it.

More methods for the weight determination were applied so that the results could be compared. It is difficult to decide which method gives better results because in the higher and lower values there are significant differences in the weight values. The values of weights are similar in the middle part.

Multicriteria decision making process offers methods that are suitable for selection of the best option. This option meets the largest spectrum of the chosen criteria. The utility of the options was determined by The Weighted Sum Method including Aggregated Utility Function. The difference between the best and the worst option using The Order Weight Method is 0.41 . This is a big difference and it shows that the worst option is not suitable for the requested monitoring. The best option

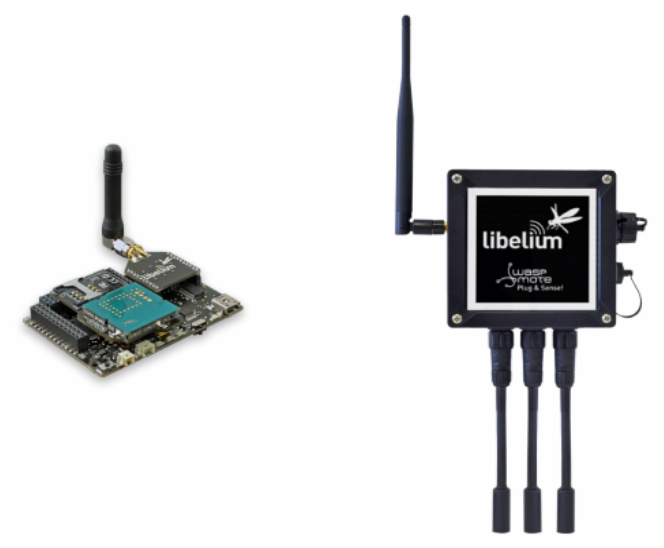

Figure 5. Waspmote Plug \& Sense.

utility value is 0.75 and this option fulfills the criteria evaluated by the highest values. The Waspmote Plug \& Sense nodes represent the best option for this particular application. Not only nodes but the other WSN components compatible with these nodes are highly evaluated. Waspmote Plug\&Sense node complies all the weight most evaluated criteria such as gas sensors from the same producer and communication using Zigbee protocol. These nodes are directly applicable in the exterior conditions. The disadvantages of these nodes are the size and the weight (Figure 5).

\section{Acknowledgements}

The autohors acknowledge the support of the European 
Social Fund and the state budget of the Czech Republic (Project No. CZ.1.07/2.3.00/20.017). The authors also acknowledge the support of the Internal Grant Agency of Palacký University in Olomouc (Project No. PrF 2013 024).

\section{REFERENCES}

[1] A. Asín and D. Gascón, "50 Sensor Application for a Smarter World," 2013.

http://www.libelium.com/top_50_iot_sensor_applications _ranking/pdf

[2] F. L. Lewis, "Wireless Sensor Networks," 2004. http://arri.uta.edu/acs/networks/WirelessSensorNetChap0 4.pdf

[3] C. Murthy and B. S. Manoj, "Ad Hoc Wireless Networks: Architectures and Protocols," Prentice-Hall, Upper Saddle River, p. 857.

[4] S. Büttrich, "Wireless Sensor Network," 2010. https://blog.itu.dk/SPVCE2010/files/2010/11/introduction _to_wsn_-_lecture_slides_spvc2010_1.pdf

[5] A. Grilo, "Wireless Sensor Networks," Single Node Architecture. 2007.

http://comp.ist.utl.pt/ece-wsn/doc/slides/sensys-ch2-sing1 e-node.pdf

[6] M. Podhorský, "Bezdrátové Senzorové Sítě v Průmyslové Praxi," Bachelor Thesis. VUT Brno, Brno, 2012. https://dspace.vutbr.cz/handle/11012/7764?show=full

[7] A. Asín, "Sensor Network to Monitor Air Pollution in the Cities," 2010. http://www.libelium.com/smart_cities_wsn_air_pollution/

[8] A. Bielsa, "Smart City Project in Salamanca to Monitor Air Duality and Urban Traffic with Waspmote," Libelium, Spain, 2011.

http://www.libelium.com/Smart_City_Air_Quality_Urba n_Traffic_Waspmote

[9] M. Yajie, M. Richards, M. Ghanem, Y. Guo and J. Hassard, "Air Pollution Monitoring and Mining Based on Sensor Grid in London," Sensors, Vol. 8, No. 6, 2008, pp. 3602-3621.

[10] K. Leung, "Mobile Environmental Sensing System," 1998. http://www.commsp.ee.ic.ac.uk/ wiser/message/index.ht $\mathrm{ml}$

[11] J. H. Liu, et al., “An Air Quality Monitoring System for Urban Areas Based on the Technology of WSNs," Inter- national Journal on Smart Sensing and Intelligent Systems, Vol. 5, No. 1, 2012, pp. 191-214.

[12] A. Bielsa, "Smart City Project in Serbia to Monitor Environmental Parameters by Public Transportation with Waspmote," 2012.

http://www.libelium.com/smart_city_environmental_para meters_public_transportation_waspmote

[13] K. M. Tajne, et. al., "Monitoring of Air Pollution Using Wireless Sensors-A Case Study of Monitoring Air Pollution in Nagpur City," International Journal of Environmental Sciences, Vol. 2, No. 2, 2011, pp. 829-838.

[14] R. V. Y. Prasad, et al., "Real Time Wireless Air Pollution Monitoring System," ICTACT Journal on Communication Technology: Special Issue on Next Generation Wireless Networks and Applications, Vol. 2, No. 2, 2011, pp. 370-375.

[15] T. C. Keener, "WSNs for Monitoring Carbon Monoxide in Ambient Air," A\&WMA International Speciality Conference Leapfrogging Opportunities for Air Quality Improvement, Xi'an, 10-14 May 2010, pp. 201-210.

[16] J. Talašová, "Fuzzy Metody Vícekriteriálního Rozhodování," Olomouc, 2003, p. 179.

[17] V. Voženílek, “Artificial Intelligence and GIS: Mutual Meeting and Passing," International Conference on Intelligent Networking And Collaborative Systems (INCOS 2009), 2009, pp. 279-284. http://dx.doi.org/10.1109/INCOS.2009.83

[18] T. Přibylová, "Metody Rozhodování za Rizika a Jejich Použití v Ekonomické Praxi," Bachelor Thesis, University Pardubice, Pardubice, 2012. http://dspace.upce.cz/bitstream/10195/46295/2/Pribylova T_MetodyRozhodovani_OS_2012.pdf

[19] P. Tuček, V. Pászto and V. Voženílek, "Regular Use of Entropy for Studying Dissimilar Geographical Phenomena" Geografie, Vol. 114, No. 2, 2009. pp. 117-129.

[20] H. Karl and A. Willig, "Protocols and Architectures for Wireless Sensor Networks," John Wiley \& Sons, Ltd., Hoboken, 2005. http://doi.wiley.com/10.1002/0470095121

[21] P. Holešinský, "Lokalizační Techniky Bezdrátových Senzorových Sítí," Electrorevue, Vol. 6, No. 12, 2009, pp. 661- 669.

[22] J. Mizera, "Využití Senzorových Bezdrátových Sítí pro Monitorování Životního Prostředí," Bachelor Thesis, VUT Brno, Brno, 2011.

http://www.vutbr.cz/www_base/zav_prace_soubor_verejn e.php?file_id $=42512$ 